\title{
Experimental and Theoretical Study of Ketoconazole as Corrosion Inhibitor for Bronze in $\mathrm{NaCl}+\mathrm{Na}_{2} \mathrm{SO}_{4}$ Solution
}

\author{
D.E. Millan-Ocampo ${ }^{1}$, J.A. Hernandez-Perez ${ }^{1}$, J. Porcayo-Calderon ${ }^{1,}$ J.P. Flores-De los Ríos ${ }^{2}$, \\ L.L. Landeros-Martínez, V.M. Salinas-Bravo ${ }^{4}$, J.G. Gonzalez-Rodriguez, ${ }^{1, *}$, L. Martinez ${ }^{5}$ \\ ${ }^{1}$ Universidad Autonoma del Estado de Morelos, CIICAP, Av. Universidad 1001, 62209-Cuernavaca, \\ Mor.,Mexico. \\ ${ }^{2}$ Universidad Autónoma de Chihuahua, Facultad de Ingeniería. Circuito Universitario Campus II C.P. \\ 31125 Chihuahua, Chih. México. \\ ${ }^{3}$ Centro de Investigación en Materiales Avanzados S.C. Chihuahua, México \\ ${ }^{4}$ Instituto Nacional de Energías Limpias, Av, Reforma 108, Temixco, Mor., Mexico \\ ${ }^{5}$ Universidad Nacional Autonoma de Mexico, Instituto de Ciencias Fisicas, Av. Universidad S/N, \\ 62209-Cuernavaca, Mor.,Mexico. \\ *E-mail: ggonzalez@uaem.mx;tel/fax
}

doi: $10.20964 / 2017.12 .22$

Received: 16 August 2017 / Accepted: 7 October 2017 / Published: 12 November 2017

An antifungal, Ketoconazole, 1-[4-[4-[[(2R,4S)-2-(2,4-dichlorophenil)-2-(imidazol-1- ilmetil)-1,3dioxolan-4-yl]metoxi]phenil]piperazin-1-yl]ethanol, has been evaluated as corrosion inhibitor for bronze in $3.5 \% \mathrm{M} \mathrm{NaCl}+0.1 \mathrm{M} \mathrm{Na} \mathrm{SO}_{4}$ solution with electrochemical techniques, including potentiodynamic polarization curves, linear polarization resistance and electrochemical impedance spectroscopy measurements at different concentrations and temperatures. Additionally, theoretical studies have been performed by using density functional theory (DFT) in order to know the relationship between the electronic properties of Ketoconazole and its inhibitive effect. Results show that Ketoconazole turned out to be a good mixed type of inhibitor, which is adsorbed in a physical way on to the metal surface by following a Langmuir type of adsorption isotherm. Inhibitor efficiency increases with time and inhibitor concentration, but it decreases with an increase in the temperature.

Keywords: Corrosion, antifungal, bronze.

\section{FULL TEXT}

(C) 2017 The Authors. Published by ESG (www.electrochemsci.org). This article is an open access article distributed under the terms and conditions of the Creative Commons Attribution license (http://creativecommons.org/licenses/by/4.0/). 